\title{
The Association Between Screen Media Quantity, Content, and Context
}

\section{and Language Development}

\author{
Haifa Alroqi ${ }^{1,2}$, Ludovica Serratrice ${ }^{3}$, Thea Cameron-Faulkner ${ }^{1}$
}

${ }^{1}$ School of Arts, Languages and Cultures, University of Manchester, UK

${ }^{2}$ Department of European Languages and Literature, King Abdulaziz University, Saudi Arabia

${ }^{3}$ School of Psychology and Clinical Language Sciences, University of Reading, UK

Corresponding author: Haifa Alroqi, School of Arts, Languages and Cultures, University of Manchester, UK. Email: halroqi@ kau.edu.sa

Funding: This work was part of a PhD scholarship supported by King Abdulaziz University, Jeddah, Saudi Arabia.

Financial Disclosure: The authors have no financial relationships relevant to this article to disclose.

Conflict of Interest: The authors have no conflicts of interest relevant to this article to disclose. 


\begin{abstract}
This study investigates the influence of the quantity, content, and context of screen media use on the language development of 85 Saudi children aged 1 to 3 years. Surveys and weekly event-based diaries were employed to track children's screen use patterns. Language development was assessed using an Arabic Communicative Development Inventory (CDI). Findings indicate that the most significant predictor of expressive and receptive vocabulary in 12- to 16-month-olds was screen media context (as measured by the frequency of interactive joint media engagements). In older children (17- to 36-month-olds), more screen time (as measured by the amount of time spent using screens, the prevalence of background TV at home, and the onset age of screen use) had the highest negative impact on expressive vocabulary and mean length of utterance. These findings support health recommendations on the negative effects of excessive screen time and the positive effects of co-viewing media with children.
\end{abstract}

Keywords: screen time, co-viewing, vocabulary, language development, media use, toddlers, children 
Screen time is nowadays an integral part of young children's lives in many parts of the world wherever they have access to content delivered via TVs, and - increasingly more commonly - via computers, tablets, and smartphones. Examining the relation between screen media exposure and language development in the first few years of life is of extreme importance as it is well established that these early stages are a time of rapid and substantial neural, cognitive, and linguistic development (Bornstein, 2015; Rodriguez et al., 2009). The reported findings to date on the association between screen media use and children's language development vary widely across studies based on their differing foci on variables such as the child's age, the screen medium examined (e.g., television, touchscreen, computer), screen media parameters (quantity, content, or context), and language outcomes (e.g., expressive language skills, receptive language skills, novel word learning, imitation). The aim of this study is to examine the predictive relationship between the aforementioned three screen media use parameters (quantity, content, and context) and language outcomes among children under 3.

\section{Screen Media Use and Language Development}

The association between screen media exposure, which we consider as an integral element of the environment, and language development is examined by drawing on Bronfenbrenner (1979)'s ecological systems theory. Bronfenbrenner (1979) focuses on the social contexts in which children live and posits that their development is influenced by the reciprocal interactions between a series of nested ecological systems (i.e., microsystem, mesosystem, exosystem, macrosystem, and chronosystem). When ecological systems theory was first introduced in 1979, television was the prevalent technology available to children. Television was considered by Bronfenbrenner (1979) to be part of the child's exosystem because it enters the child's home from an external source. This powerful medium influences parents and parent- 
child interactions, and thus it operates not just within the child's microsystem, but rather across the child's ecological borders.

Johnson and Puplampu (2008) introduced the ecological techno-subsystem as a dimension of the microsystem to account for the presence of the Internet within the ecological system. The techno-subsystem includes children's interaction with their microsystem (i.e., immediate environments) via technology.

Bronfenbrenner (1979) coined the term molar activity, defining it as "an ongoing behavior possessing a momentum of its own and perceived as having meaning or intent by the participants in the setting" (Bronfenbrenner 1979, p. 45), and highlighted the significance of molar activities on learning and development. Experiences and activities do not play equal roles in children's development; some occur infrequently and/or are not very significant, whereas others (molar activities) occur frequently and have more notable influences on development (Lauricella et al., 2015). Given the important presence of screen media across different contexts within children's ecological systems, along with the increasing amount of time spent by children and adults engaged with screens, children's and parents' media use, parental attitudes towards media, and parental media mediation practices can all be regarded as molar activities in children's environments (Lauricella et al., 2015).

One of the major concerns associated with children's excessive use of screens is the reduction, or even possible displacement, of real-life social interactions (Dore et al., 2020; Dynia et al., 2021). This possibility is particularly important in light of the fact that these types of interactions are an essential component of ecological systems theory. Indeed, the concern about time displacement is not new. Bronfenbrenner (1979) talked about the lure of television and of its power to turn children into passive and silent spectators. 


\section{Association Between Screen Media Use and Language Development}

In this section, we review the literature on three screen media parameters: quantity, content, and context for children under the age of 5.

\section{Quantity of Screen Media Exposure}

Research on the quantity of screen media exposure typically involves (a) the onset age at which children start using screens, which contributes to the total cumulative amount of time children are exposed to screens, and (b) the amount of foreground exposure (time children spend actively engaged with screens) and background exposure (time children spend being exposed to screens in the background without actively viewing or using them). Few studies have specifically looked at the association between the onset age at which screen media viewing starts and language outcomes. So far, the evidence suggests that children who start using screens at earlier ages have lower language outcomes than those who start later (Chonchaiya \& Pruksananonda, 2008; Hudon et al., 2013; Supanitayanon et al., 2020).

A small number of studies have found positive associations between the quantity of screen media exposure and language outcomes (e.g., Linebarger \& Walker, 2005; Roseberry et al., 2014). However, the majority of the studies that examined the relation between the quantity of foreground and background screen media exposure and language outcomes in young children point to either negative relations (e.g., Chonchaiya \& Pruksananonda, 2008; Duch et al., 2013; Dynia et al., 2021; Hill et al., 2020; Hudon et al., 2013; Madigan et al., 2019; Supanitayanon et al., 2020; van den Heuvel et al., 2019) or non-significant relations (e.g., Alloway et al., 2014; Schmidt et al., 2009; Taylor et al., 2018). 


\section{Content of Screen Media}

Screen media content types available to children vary and they differ in several aspects including the audience that they target (i.e., child-directed vs. adult-directed), their educational value (i.e., educational vs. non-educational), and the languages that they use (e.g., child's first language, child's second language, a foreign language). Variation in these aspects of screen media content has been linked to a range of language and learning outcomes.

A number of longitudinal studies have shown that young children's viewing of programs that are not age-appropriate is negatively associated with language and cognitive outcomes (e.g., Barr et al., 2010; Wright, Huston, Murphy, et al., 2001). Adult-directed programs have also been found to reduce the quality and quantity of parent-child interactions, which are significant predictors of child language development (e.g., Kirkorian et al., 2009).

Educational benefits are among the most frequent motives that parents cite for allowing their children to use screens (Bentley et al., 2016; Li et al., 2017). Several studies have found positive associations between viewing specific children's educational programming (e.g., Sesame Street, Arthur, Clifford, Dragon Tales, Dora the Explorer, and Blue's Clues) and language outcomes in children above the age of 2 years (e.g., Linebarger \& Walker, 2005; Wright, Huston, Scantlin, et al., 2001). However, children younger than 2 do not seem to gain similar benefits from watching educational shows (e.g., DeLoache et al., 2010; Krcmar, 2014; Tomopoulos, et al., 2010). This adds to accumulating evidence that children under 2 do not learn as effectively from screen media as they do from live presentations (e.g., Neuman et al., 2014; Roseberry et al., 2009), in what has been named the video deficit effect (Anderson \& Pempek, 2005).

The language input received from screen media is an important aspect to consider, especially in communities where the language variety used in screen media is different from the 
variety that children hear in daily conversations around them. Some studies have found negative associations between children viewing screen media in a language other than the language spoken at home and their first language development (e.g., Duch et al., 2013).

\section{Context of Screen Media Exposure}

The social context of screen media use refers to whether screen media is viewed with other people or individually. Two or more people watching television together has been described for many years as co-viewing (Austin, 1993; Valkenburg et al., 1999). Joint Media Engagement (JME), a more recent term, is sometimes used to refer to both TV co-viewing and mobile media co-using (Takeuchi \& Stevens, 2011). Co-viewing of educational programs with contingently responsive adults has been found to have better outcomes such as better attentiveness, novel word learning, and expressive vocabulary growth than solitary viewing (e.g., Myers et al., 2018; Rasmussen et al., 2017; Strouse et al., 2018). Contingency refers to the follow up on the child's current focus of attention whereas Responsiveness refers to a caregiver's sensitivity to a child's attempts to interact, recognition of child's cues and needs, and responding to these attempts, signals, and needs appropriately and promptly (Matthews et al., 2016;

McGillion et al., 2017). According to the latest screen time recommendations from the American Academy of Pediatrics (2016), interactive co-viewing is the primary factor in facilitating toddlers' word learning from screens.

\section{The Current Study}

Our review of the literature revealed a number of gaps that require attention. First, children under 3 years are under-represented in research and in governmental and think tanks' reports into the impact of screen media use on children's health and development in general, and on language development specifically. For example, the UK's Office of Communications 
(Ofcom) publishes annual reports on adults and children's media use and attitudes, but they only examine children aged 3 years and older. Similarly, EU Kids Online publishes yearly reports on children's media use in Europe but does not report data on children under 3. By focusing on children under the age of 3 years in this study, we are targeting a critical time in children's emergent receptive and expressive language skills. Early childhood is also a crucial period for the establishment of lifelong media habits and routines and a critical window for intervention (Radesky \& Christakis, 2016).

Second, non-Western cultures are under-represented in the literature, as most of what is known about children's screen media use and its effects on language development comes from North America and Europe. To the best of our knowledge, this is the first study to investigate the association between screen media exposure and language development in young children in the Middle East and North Africa (MENA) region. Saudi Arabia, the setting for our fieldwork, provides a unique setting for this study as it is the largest media market in the MENA region (Dubai Press Club \& Dubai Media City, 2016), and the world's highest per capita consumer of YouTube (Smith, 2013). Furthermore, the significance of conducting research on this young population is particularly important in Saudi Arabia, a demographically young country with a population of over 32 million, where almost $40 \%$ are under the age of 20 , with $10 \%$ under the age of 4, the largest age group in the country (Saudi General Authority for Statistics, 2016).

Third, research to date has tended to focus on the association between television and children's health and development. Recent investigations that examined effects of new media on children seemed to exclude traditional media, although it is important to understand that children and adults today usually engage in multitasking with media. For example, the family could be sitting in the living room watching television together and at the same time each of the family 
members could be engaged with their mobile media device. Therefore, any investigation of screens should take into account the various outlets used to access media content.

Finally, most of the public debate and research efforts to date have mainly focused on either the quantity, content, or context of screen media use. Very few studies have comprehensively examined the impacts of all three aspects together. In order to better understand the screen media use practices of children and the associations between these practices and their language development, we examined the extent to which each of the three screen media use parameters (quantity, content, and context) predict language outcomes among children under 3.

\section{Methods}

\section{Participants}

The final sample in the present study consisted of 85 1- to 3-year-old Saudi children residing in Saudi Arabia. The study started with an initial sample of 139 participants. Nearly $75 \%(n=104)$ of the potential participants were eligible to participate in the study. Only stay-athome children (those who do not attend day care) were eligible to enter the study. In Saudi Arabia, children typically do not start daycare before 3 therefore our sample is representative of the population. Attrition rate over the course of the study was $18 \%(N=19)$.

The mean age of the 85 children in the final sample was 24.92 months $(S D=7.67$ months). Tables 1 provide details of the socioeconomic characteristics of the target children and their parents. 
Table 1

Socioeconomic Characteristics of the Parents, Households, and Children

\begin{tabular}{|c|c|c|c|c|}
\hline \multirow[t]{2}{*}{ Parental SES variable } & \multicolumn{2}{|c|}{ Mothers } & \multicolumn{2}{|c|}{ Fathers } \\
\hline & $n$ & $\%$ & $n$ & $\%$ \\
\hline \multicolumn{5}{|l|}{ Age } \\
\hline 20-29 years & 53 & 62.35 & 19 & 22.35 \\
\hline 30-39 years & 31 & 36.47 & 50 & 58.82 \\
\hline $40-49$ years & 1 & 1.18 & 15 & 17.65 \\
\hline Older than 50 years & 0 & 0.00 & 1 & 1.18 \\
\hline \multicolumn{5}{|l|}{ Education } \\
\hline Postgraduate degree & 10 & 11.76 & 7 & 8.24 \\
\hline Bachelor's degree or some education after high school & 61 & 71.76 & 53 & 62.35 \\
\hline High school certificate & 13 & 15.29 & 20 & 23.53 \\
\hline Intermediate or primary school certificate & 1 & 1.18 & 4 & 4.71 \\
\hline No schooling completed & 0 & 0.00 & 1 & 1.18 \\
\hline \multicolumn{5}{|l|}{ Occupation } \\
\hline Employed & 22 & 25.88 & 84 & 98.82 \\
\hline Unemployed & 51 & 60.00 & 1 & 1.18 \\
\hline Student & 12 & 14.12 & 0 & 0.00 \\
\hline \multicolumn{5}{|l|}{ Language spoken with child } \\
\hline Arabic & 63 & 74.12 & 80 & 94.12 \\
\hline English & 0 & 0.00 & 1 & 1.18 \\
\hline Both Arabic and English & 22 & 25.88 & 4 & 4.71 \\
\hline Household characteristics & $n$ & $\%$ & & \\
\hline \multicolumn{5}{|l|}{ Monthly household income ${ }^{a}$} \\
\hline Lower-income & 40 & 47.06 & & \\
\hline Middle-income & 31 & 36.47 & & \\
\hline Higher-income & 14 & 16.47 & & \\
\hline
\end{tabular}




\begin{tabular}{lll}
\hline Availability of domestic helper/nanny & & \\
Yes & 21 & 24.71 \\
No & 64 & 75.29 \\
\hline Child's age & & \\
$12-16$ months & 18 & 21.18 \\
$17-36$ months & 67 & 78.82 \\
\hline Child's gender & & \\
Female & 39 & 45.88 \\
Male & 46 & 54.12 \\
\hline
\end{tabular}

${ }^{\text {a }}$ For the purpose of this study, lower-income was defined as families earning less than SAR 10,000 a month; middle-income was families earning between SAR 10,000 and SAR 19,999 a month, and higher-income was families earning over SAR 20,000 a month (SAR 1 = USD0.267 as of March 1, 2021; SAR = Saudi Arabian Riyal). According to the Saudi General Authority for Statistics, the median monthly household income in 2013 was SAR 10,723 (The Saudi General Authority for Statistics, 2013).

\section{Procedures}

All participation in this study was voluntary. Ethical approval for the study was received from the first author's university's research ethics committee. Participants were recruited via several social media platforms. All materials used in this study were administered in Arabic.

Each participant was sent (via email) a Home Literacy and Media Diary (described below), with detailed instructions on how to complete it and an example of a completed 1-day diary. Each participant was asked to complete seven daily diaries over a period of 7 weeks. Completed diaries were collected (via email or WhatsApp) from participants on a weekly basis and checked regularly to address any immediate problems or incorrect entries. After completing the fourth diary, each participant was asked to complete a hard copy of the JISH Arabic Communicative Development Inventory (JACDI; Dashash \& Safi, 2014), either the Words and Gestures (JACDI-WG) version for children between 12 to 16 months, or the Words and 
Sentences (JACDI-WS) version for children between 17 and 36 months. Participants were contacted by phone by the first author and were given instructions on how to complete the JACDI. After submitting the last diary, each participant was sent a link to complete the Home Literacy and Media Survey (described below) via the online data collection engine Survey Monkey.

The final sample included all participants who submitted at least two diaries for at least one weekday and one weekend day, completed the language assessment tool, and completed the online survey. Out of the 85 participants in the final sample, 52 submitted seven diaries, 24 submitted two diaries, and nine submitted more than two but fewer than seven diaries.

\section{Materials and Measures}

The primary caregivers completed three measures relating to their child's screen media exposure: (1) a home literacy and media diary, (2) a vocabulary assessment tool, and (3) a home literacy and media survey. Details of each measure are described below.

\section{The Home Literacy and Media Diary (HLM Diary)}

The Home Literacy and Media (HLM) Diary (see Supplementary Materials) is a 24-hour, event-based, parent-report diary that aims at collecting data on target children's media use, reading, and play activities. It was adapted from the Child Development Supplement to the Panel Study of Income Dynamics (PSID-CDS; University of Michigan Institute for Social Research, 2014).

Each participant was asked to log their target child's activities as they occurred over the course of one chosen day each week for a period of 7 weeks with the aim of having a total of 5 different weekdays and 2 different weekend days. Screen time per day was calculated by adding 
up the number of minutes spent daily in viewing screens then dividing it by the number of diaries submitted.

\section{The JISH Arabic Communicative Development Inventory (JACDI)}

The JISH Arabic Communicative Development Inventory (JACDI; Dashash \& Safi, 2014) is a standardized, norm-referenced measure designed to assess Saudi Arabic vocabulary development in infants and toddlers aged 8 to 36 months. It is the Saudi Arabic adaptation of the MacArthur-Bates Communicative Development Inventories (CDI; Fenson et al., 1993). It includes the JACDI-WG for 8- to 16-month-old children (which was used in this study to assess receptive and expressive vocabulary) and JACDI-WS for 17- to 36-month-old children (which was used in this study to assess expressive vocabulary and mean length of utterance).

\section{The Home Literacy and Media Survey (HLM Survey)}

The Home Literacy and Media (HLM) Survey (see Supplementary Materials) was used to collect specific information about the target children's screen media and literacy environment. The HLM Survey consists of 84 questions; thirteen survey items were adapted from the Common Sense Media Zero to Eight Survey (Rideout, 2013) and the Parenting in the Age of Digital Technology Survey (Wartella et al., 2014). The remainder of the survey items were developed by the first author. In order to limit the scope of this paper, we did not analyse the survey items that pertain to parental attitudes toward their children's media use or parental screen media mediation practices and styles, which are not investigated in this study. Items were presented in various formats including yes/no questions, checklists, open-ended questions, and Likert scales.

Both data collection tools (the diary and the survey) were utilized to collect in-depth information from the respondents and contributed to specific research questions. For example, the amount of foreground screen media exposure, the types of contents viewed on screens, 
details of the social context of screen media use, and the frequency of reading and play activities were all captured using the diary. However, it was not possible to collect some information using the diary tool such as demographic information of children and their parents, the age at which children started using screens, the availability of internet connection at home, and the number of media devices and books at home, therefore, the survey tool was used to collect these specific data.

To ensure face validity, the survey and the diary were pilot-tested on a small group of mothers of 1- to 3-year-olds for clarity, readability, errors, and completion time, and changes were made accordingly.

\section{Analysis}

Statistical analysis was performed in $\mathrm{R}$ (version 3.4.2). Descriptive statistics were used to assess measures of central tendency and variability. When examining the amount of time children spend using screens, we divided the children into two age groups based on international guidelines on screen time that make a distinction between screen time recommendations for children above and below 2 years. Thus, we divided the children here into a younger group aged 1 to 2 years ( $n=42, M=18.17$ months, $S D=3.87$ months $)$ and an older group aged 2 to 3 years ( $n=43, M=31.51$ months, $S D=3.61$ months).

Regression analyses were utilized to answer our primary research question. For the regression analyses, the sample was divided into two age groups according to the two JACDI versions: younger children aged $12-16$ months ( $n=18, M=14.39$ months, $S D=1.33$ months) and older children aged 17-36 months $(n=67, M=27.75$ months, $S D=6.01$ months $)$. In order to select the best regression model, we used stepwise model selection, which utilizes the Akaike Information Criterion (AIC) to eliminate the non-significant predictors. In addition, we used the 
F-ratio test to help us decide whether to use the full or reduced model. The predictor and outcome variables are described below.

\section{Predictor Variables}

Our main predictor variables were screen media quantity, screen media content, and screen media context. We were also interested in comparing the prevalence of screen media in children's home environments with the prevalence of reading, which has been long regarded as the most substantial component of the Home Literacy Environment (HLE). Reading, family socioeconomic status (SES; as indexed by parental education, parental employment, and household income) and child gender were included in the model as predictors to explore their effects on the outcome variables.

The predictor variables were grouped into five broad composite categories: (1) screen media quantity, (2) screen media content, (3) screen media viewing context, (4) reading prevalence, and (5) family SES. Gender was later added to the regression model as a factor. Table 2 provides more details on the variables included within each category and the scores that were assigned to each variable. Each composite category was given a composite global score. For the screen media categories, higher scores were given to conditions that have been described in the literature as "more positive" screen media viewing experiences. For example, a higher score was given to a child who views screens for less than 2 hours a day, who rarely has TV on at home when no one is watching, who started viewing screens after the age of 2 , who watches child-directed educational content more than other content types, who mostly watches screen media content in their mother tongue, and who is mostly accompanied by an interacting adult while watching. With regard to the reading prevalence category, higher scores were given to conditions where reading was more frequent, and children had access to more books at home. As 
for the family SES category, higher scores were given to conditions where parents were more highly educated, were employed, and had a higher monthly income.

Screen Media Quantity. In order to determine quantity of screen media exposure, we considered: (1) the average amount of time a child spends daily viewing screens (TV and mobile media devices), (2) the frequency of background TV exposure (which adds to the total screen media exposure time), and (3) the onset age of screen media viewing (TV and mobile media devices).

Screen Media Content. To determine quality of screen media content, we used three variables: (1) target audience (i.e., child-directed content vs. adult-directed content); (2) content genre (i.e., child-directed educational content, child-directed non-educational content, childdirected songs and rhymes); and (3) language/language variety of the content viewed (i.e., Modern Standard Arabic (MSA), Saudi/Gulf Colloquial Arabic, Non-Saudi/Gulf Colloquial Arabic, English, no speech [silent, noise or music only]). For each child, we identified the most viewed/used screen media content type (i.e., the content type viewed/used for periods longer than the other types).

To decide whether a show was educational or non-educational, we used the Common Sense Media (CSM) evaluation of educational value for each show (Common Sense Media, 2017). If a show was rated by CSM at least 3 out of 5 for educational value, it was considered educational. It is worth noting that most of the shows that Saudi children watch on TV and mobile media devices are international shows that are also aired on American and British channels, but are dubbed in Arabic. For the shows that could not be found on CSM (e.g., local shows and shows produced specifically for an Arabic-speaking audience), we viewed five different episodes or video clips of each show and determined its educational value. We followed 
Zimmerman and Christakis' (2007) method of content classification. Any show that was designed to have primarily educational value for children was considered educational. Any show that was designed to be primarily entertaining for children was considered non-educational.

Screen Media Viewing Context. To determine the social context of viewing, we looked at two variables: (1) solitary viewing vs. co-viewing; and (2) interactive co-viewing (verbal interaction while co-viewing) vs. passive or silent co-viewing (no verbal interaction while coviewing). Similar to how we calculated the most frequently viewed content types, for each child, we identified the most frequent type of viewing context based on the number of total minutes that they engaged in each type. For example, if a child spent more time viewing media alone than co-viewing media with another person, their most frequent type of social context would be solitary viewing.

Reading Prevalence. To determine the prevalence of reading in the child's environment, we looked at two variables: (1) how often the child is read to at home; and (2) the number of books available to the child at home.

Family SES. To assess family SES, we looked at five variables: (1) mother's educational attainment, (2) father's educational attainment, (3) mother's employment, (4) father's employment, and (5) monthly household's income. 
Table 2

Broad Composite Categories of the Predictor Variables

\section{Media Quantity}

Overall screen time

Frequency of background TV

Onset age of TV viewing

Onset age of mobile media use

\section{Media Content}

Most viewed content target audience

Most viewed content genre

Most viewed content language

\section{Media Context}

Frequency of co-viewing TV

Frequency of co-using mobile media

Frequency of interaction while coviewing

\section{Reading Prevalence}

Number of books available to child

Frequency of reading to child

\section{Family Demographics}

Mother's education

Father's education

Mother's employment

Father's employment

Monthly household income

\begin{tabular}{c} 
Source \\
\hline Diary \\
Survey (Item 65-10) \\
Survey (Item 75) \\
Survey (Item 76)
\end{tabular}

Diary

No use

Diary

No use

IDK

1

(

Score

$>2$ hours

$\leq 12$ months
$\leq 12$ months

$\leq 2$ hours
Rarely/Sometimes
$13-24$ months
$13-24$ months
Child-directed
Child-directed
educational
Colloquial non-
Gulf Arabic

Adult-directed

Child-directed non-

educational/Child-

directed songs

English/No speech

No use

Solitary viewing

Solitary use

With children

With children

No interaction

Interaction

Source

o

12

$\begin{array}{cc}\text { Survey (Item 41) } & 0 \text { books } \\ \text { Diary } & \text { Never }\end{array}$

$1-9$ books
Once a week

10-19 books

Twice a week

3-5 times a week

With adults

With adults

0 hours (no use)
Never
$\geq 25$ months/Not ye
$\geq 25$ months/Not ye

Survey (Item 13) No schooling

Elementary,

Intermediate

High school

Post HSC, Bachelor

High school

Post HSC, Bachelor

Intermediate

Employed

Survey (Item 14) Not employed

Survey (Item 20)

Not employed

Student

Employed

Survey (Item 26) $\quad<$ SR 10,000

SR 10,000 to 19,999

4

-
-
-
-
-
-
ar Saudi or
Arabic

Gulf Arabic

Note. NA = Not applicable; IDK = I don't know; MSA = Modern Standard Arabic; HSC = High School Certificate. 


\section{Outcome Variables}

The outcome variables were derived from the JACDI. For the children aged 12 to 16 months $(n=$ $18, M=14.39$ months, $S D=1.33$ months), the outcome variables were expressive and receptive vocabulary size as measured by the JACDI-WG. For the children aged 17 to 36 months ( $n=67$, $M=27.75$ months, $S D=6.01$ months), we used the JACDI-WS to assess expressive vocabulary size (i.e., the number of words produced) since the JACDI-WS does not assess receptive vocabulary for children above 16 months, and mean length of the three longest utterances (M3L).

\section{Results}

In this section, we first report descriptive information on the screen media use and reading practices among children in our sample and then move on to address our primary research question: To what extent does each of the three screen media use parameters (quantity, content, and context) predict language outcomes among children under 3.

\section{Descriptive Statistics}

\section{Quantity of Screen Media Exposure}

Quantity of Foreground Screen Media Exposure. Based on the diary data, compared to time spent in book reading and indoor play and/or outdoor play, screen media viewing/using was the most prevalent activity among Saudi young children (Figure 1). Children in the sample (including those who had never engaged in one or more of the activities) spent an average of 149.26 minutes $(S D=108.32$ minutes) daily exposed to screens $(\mathrm{TV}: M=84.11$ minutes, $S D=$ 63.24 minutes; mobile media: $M=65.12$ minutes, $S D=78.96$ minutes). They only spent an average of 7.77 minutes $(S D=16.01$ minutes $)$ a day in shared-book reading, and an average of 
134.79 minutes $(S D=79.39$ minutes) a day in play (indoor play: $M=118.44$ minutes, $S D=$ 74.35 minutes; outdoor play: $M=16.35$ minutes, $S D=26.13$ minutes).

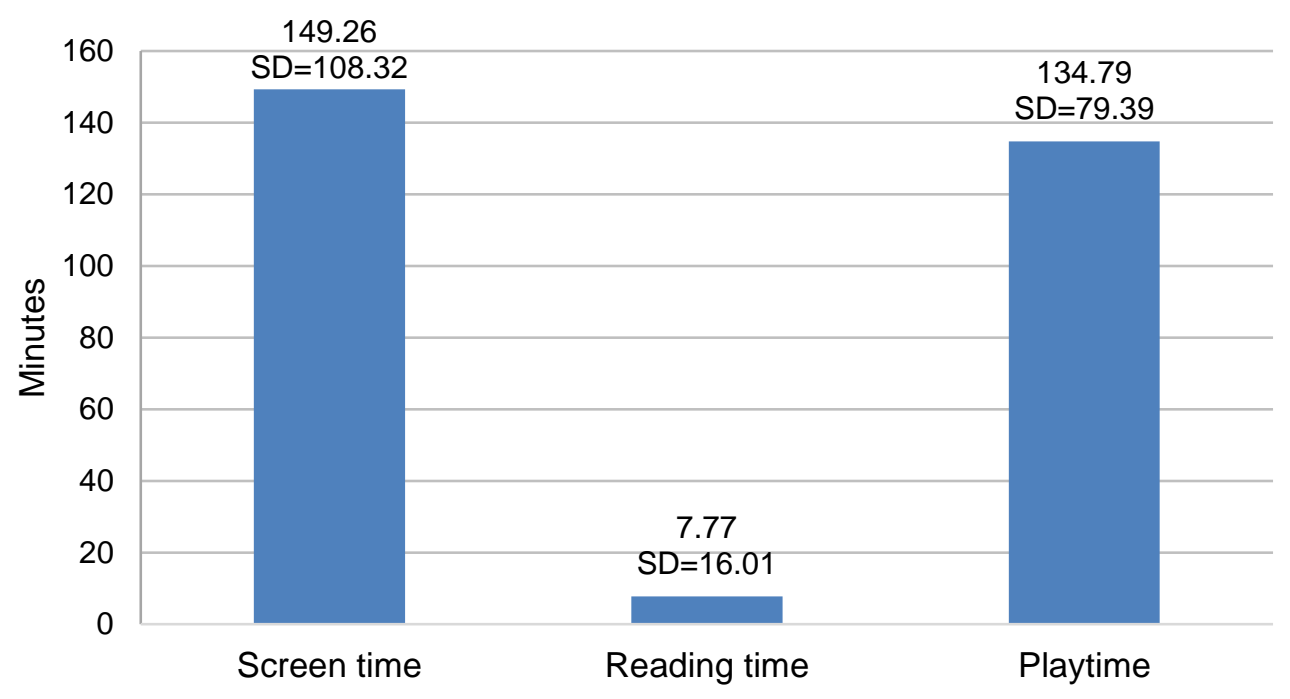

Figure 1. Children's time spent on daily activities.

The boxplots in Figure 2 show the distribution of time spent in different activities (including children who were never engaged in any of the activities). It should be noted that $7 \%$ of the children in the sample had never watched TV, $14 \%$ had never viewed mobile media, $2 \%$ were never exposed to screen media (TV and mobile media), $60 \%$ were never read to, and $47 \%$ had never played outdoors. The diary data is in stark contrast to what mothers reported in the survey about their evaluation of their children's screen time; the majority indicated that their children watch TV and use mobile media "moderately" or "rarely" (TV: 79\%; mobile media: $72 \%$ according to the survey data). 


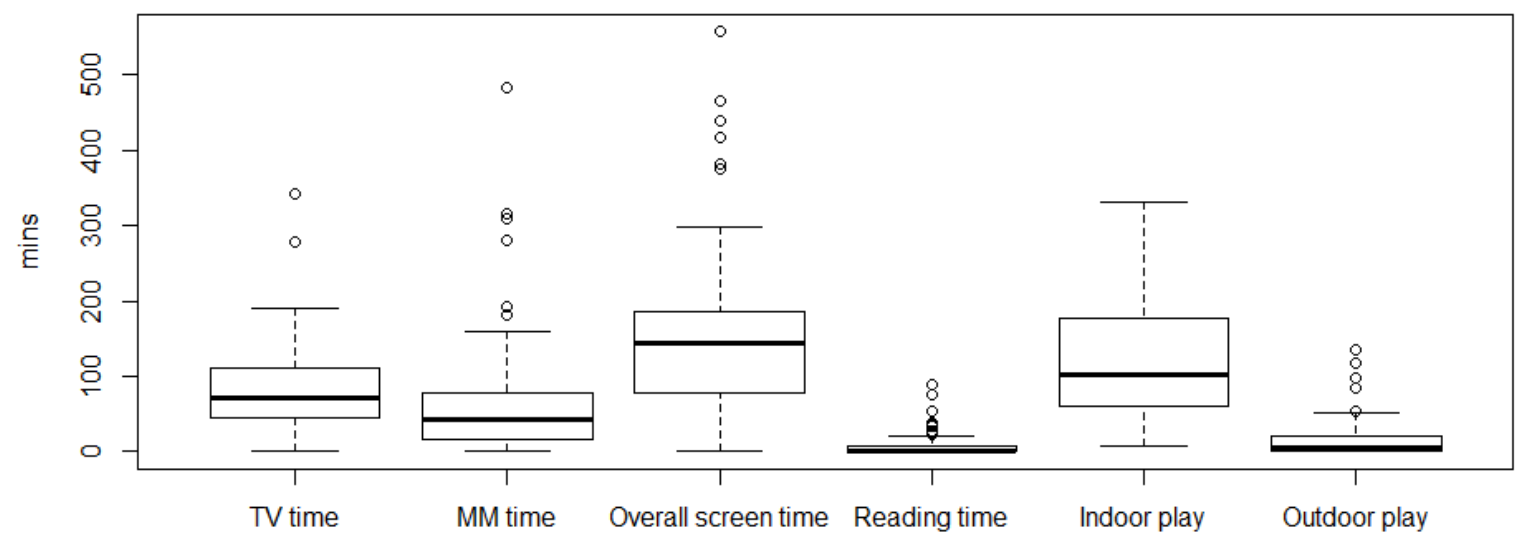

Figure 2. Distribution of time children spent in activities. Includes children who had never engaged in one or more of these activities. The bold horizontal lines represent median values. $\mathrm{MM}=$ Mobile media.

We compared the two age groups with regard to their screen time and found that $95 \%$ of all children below 2 and $91 \%$ of all children above 2 in the sample exceeded screen time recommendations by the World Health Organization (2019) and the American Academy of Pediatrics (2016) which both call for no screen time for children under 2 and no more than 1 hour for children aged 2-5 years. Older children (2 to 3 years) viewed TV and used mobile media devices significantly more frequently than younger children (1 to 2 years) (younger age group: $M$ $=117.24$ minutes, $S D=86.43$ minutes; older age group: $M=180.53$ minutes, $S D=118.95$ minutes; $t(83)=2.80, p=.006)$.

Prevalence of Background Screen Media Exposure. Over half of the mothers (59\%) indicated that TV was "often" (32\%) or "always" (27\%) left on in the background at their homes even if no one was actually watching it.

Onset Age of Screen Media Exposure. The average age of starting to watch TV among 1- to 3-year-old children was about 13 months $(M=12.76 ; S D=7.38)$, while the average age of starting to view or use mobile media was about 18 months $(M=17.82 ; S D=7.43)$. Fifty-six 
percent of the children in the sample started watching TV at the age of 2 years or earlier, and $78 \%$ started using mobile media at the age of 2 years or earlier.

\section{Content of Screen Media Exposure}

Content of Screen Media Based on Target Audience. Based on the diary data, children in the sample watched child-directed media more than adult-directed media on both screen types (TV: 83\%; mobile media: $87 \%$ ).

Content of Screen Media Based on Genre. The most viewed media content genre on all screens, as per the diary data, was child-directed non-educational content (viewed the most by $56 \%$ of the sample), followed by children's songs and rhymes (Arabic songs on TV and Arabic and English songs on mobile media, viewed the most by $35 \%$ of the sample). The most frequently viewed content genre on TV alone was child-directed non-educational content (55\%), which was the most frequently viewed content type among only $24 \%$ of mobile media users. Child-directed educational programming was more often viewed on mobile media screens (13\%) than on TV screens (5\%). The most frequently viewed content type on mobile media devices was children's songs and rhymes (44\%), viewed the most on TV by $40 \%$ of the sample. Two additional content genres were included when exploring the types of content young children viewed on mobile media devices: unboxing videos and browsing photos and videos, as we found that these are additional genres children frequently view on mobile media devices. Browsing photos and videos on mobile media devices was the most frequently viewed content on mobile media devices in $13 \%$ of the sample, while watching unboxing videos was the most frequently viewed content in $7 \%$ of the sample. 
Content of Screen Media Based on Its Language Variety. The diary data showed that the most viewed language variety on TV was MSA (58\% vs. $32 \%$ among mobile media users), followed by Non-Saudi/Gulf Colloquial Arabic (22\% vs. 5\% among mobile media users). The most viewed language variety on mobile media devices was English (37\%), though English accounted for only $6 \%$ of TV viewing.

\section{Social Context of Screen Media Viewing}

Solitary Viewing Vs. Co-Viewing. Co-viewing/co-using screens with mothers was the most frequent type of viewing among both TV viewers (55\%) and mobile media users (43\%) as per the diary data. On all screen types, co-viewing media with fathers was not the most frequent type of viewing for any of the children in the sample. Co-viewing/co-using media with both parents was the most frequent form of viewing in $12 \%$ of TV viewers, while no mobile media users were found to have co-viewing with both parents as being the most frequent type of viewing. Co-viewing was more frequent on all screen types than solitary media use. Solitary viewing/using was far more common in mobile media use (36\%) than in TV viewing (3\%).

Interactive Co-Viewing Vs. Passive Co-Viewing. Passive co-viewing of TV was more common than interactive co-viewing, as the diary data revealed that it was the most frequent type of co-viewing in $73 \%$ of the sample. No comparable data was available for mobile media co-use.

Prevalence of Reading. Reading to young children in our sample was very infrequent as per the diary data. Nearly two thirds $(60 \%)$ of the mothers in this study "never" read to their children, and only $9 \%$ read to their children every day. In addition, over one third (34\%) of the children in the sample had no books at home, 15\% had 1-2 books, and 29\% had 3-9 books. 


\section{Regression Analyses}

Table 3 and Table 4 show the descriptive statistics for the composite measures and outcome variables that were included in the regression models for each age group.

Table 3

Descriptive Statistics for the Composite Measures and Outcome Variables Included in the Regression Models for Children Aged 12 to 16 Months

\begin{tabular}{llllllll}
\hline & Min & Q1 & Mdn & $\boldsymbol{M}$ & Q3 & Max & SD \\
\hline $\begin{array}{l}\text { Outcome Variable } \\
\quad\end{array}$ & 4.00 & 8.25 & 15.00 & 23.33 & 40.50 & 55.00 & 18.37 \\
$\quad$ No. of words produced & 15.00 & 57.50 & 113.00 & 133.67 & 169.75 & 360.00 & 104.40 \\
$\quad \begin{array}{l}\text { No. of words understood } \\
\text { Composite Measure }\end{array}$ & & & & & & & \\
$\quad$ Composite score of media quantity & 5.00 & 7.00 & 8.00 & 8.17 & 9.00 & 12.00 & 1.65 \\
$\quad$ Composite score of media content & 4.00 & 5.00 & 5.00 & 5.21 & 6.00 & 7.00 & 0.89 \\
$\quad \begin{array}{l}\text { Composite score of media context } \\
\quad \text { Composite score of reading prevalence }\end{array}$ & 5.00 & 6.00 & 7.00 & 6.82 & 8.00 & 8.00 & 1.25 \\
$\quad$ Composite score of family SES & 6.00 & 0.00 & 1.00 & 2.00 & 4.00 & 7.00 & 2.14 \\
\hline
\end{tabular}

Note . Min = Minimum; Q1 = 1st Quartile; $M d n=$ Median; $M=$ Mean; Q3 = 3rd Quartile; Max = Maximum; $S D=$ standard deviation.

Table 4

Descriptive Statistics for the Composite Measures and Outcome Variables Included in the Regression Models for Children Aged 17 to 36 Months

\begin{tabular}{llllllll}
\hline & Min & Q1 & Mdn & $\boldsymbol{M}$ & Q3 & Max & $S \boldsymbol{D}$ \\
\hline Outcome Variable & & & & & & & \\
$\quad$ No. of words produced & 21.00 & 98.50 & 272.00 & 322.24 & 503.00 & 837.00 & 243.92 \\
$\quad$ M3L & 1.00 & 2.00 & 3.00 & 3.43 & 4.00 & 11.00 & 2.15 \\
Composite Measure & & & & & & & \\
$\quad$ Composite score of media quantity & 4.00 & 6.00 & 7.00 & 6.73 & 8.00 & 12.00 & 1.47 \\
$\quad$ Composite score of media content & 3.00 & 5.00 & 6.00 & 5.39 & 6.00 & 7.00 & 1.02 \\
$\quad \begin{array}{l}\text { Composite score of media context } \\
\text { Composite score of reading prevalence }\end{array}$ & 3.00 & 5.00 & 6.00 & 5.88 & 7.00 & 8.00 & 1.36 \\
$\quad$ Composite score of family SES & 0.00 & 0.00 & 1.00 & 1.96 & 3.00 & 7.00 & 2.14 \\
\hline
\end{tabular}

Note. Min = Minimum; Q1 = 1st Quartile; $M d n=$ Median; $M=$ Mean; Q3 = 3rd Quartile; Max = Maximum; $S D=$ standard deviation; $\mathrm{M} 3 \mathrm{~L}=$ The mean length of the three longest utterances 


\section{Younger Children: 12 to 16 Months}

We conducted a multiple linear regression examining the association between the predictors in Table 2 and the number of words understood by children aged 12 to 16 months. The multiple linear regression was fitted to the data of the younger children to estimate the degree of influence of each predictor on the number of words that these children understood. The parameter estimates of the model are shown in Table 5. p-values for all predictions showed nonsignificant effects.

Table 5

Multiple Linear Regression Coefficients for the Association Between the Predictors and the Number of Words Understood by Children Aged 12 to 16 Months: Full Model

\begin{tabular}{lcccc}
\hline \multicolumn{1}{c}{ Predictor } & $\boldsymbol{B}$ & $\boldsymbol{S} \boldsymbol{t}$ & $\boldsymbol{t}$ \\
\hline (Intercept) & -86.404 & 320.447 & -0.270 & 0.801 \\
Media quantity & -10.432 & 33.816 & -0.308 & 0.773 \\
Media content & -29.708 & 56.811 & -0.523 & 0.629 \\
Media context & 85.671 & 47.116 & 1.818 & 0.143 \\
Reading prevalence & -3.597 & 27.495 & -0.131 & 0.902 \\
Family SES & -8.725 & 24.192 & -0.361 & 0.737 \\
Gender & -23.390 & 80.013 & -0.292 & 0.785 \\
\hline
\end{tabular}

Note. $B=$ unstandardised coefficient; $S E=$ standard error.

The F-ratio test indicated no significant difference between the fitted regression model and the null model, $F(6,4)=1.58, p=.344$. Using stepwise selection, the best model was the model which only had screen media context as a predictor $(\mathrm{AIC}=97.77)$. The adjusted $R^{2}$ values for the full model $\left(R^{2}\right.$ Adujsted $\left.=0.257\right)$ and the reduced model $\left(R^{2}\right.$ Adujsted $\left.=0.56\right)$ indicated that the reduced model was a better fit in describing the variation in the number of words understood by the younger children group. There was no significant difference between the full model and the reduced model, which indicates that the additional variables in the full model did not contribute to explaining the variation in the response, $F(6,10)=0.26, p=.912$. In addition, the F-ratio test for the reduced model indicated a significant difference against the null model at significance level $\alpha=.05, F(1,9)=13.79, p=.005$. 
Table 6 shows the parameter estimates of the reduced model. Screen media context contributed significantly to explaining the variation in the number of words understood by the younger children group. A one-unit increase in the composite score of screen media context is expected to increase the number of words understood by 73.67 words.

Table 6

Multiple Linear Regression Coefficients for the Association Between the Predictors and the Number of Words Understood by Children Aged 12 to 16 Months: Reduced Model

\begin{tabular}{lcccc}
\hline \multicolumn{1}{c}{ Predictor } & $\boldsymbol{B}$ & $\boldsymbol{S E}$ & $\boldsymbol{t}$ & $\boldsymbol{p}$ \\
\hline (Intercept) & -341.831 & 137.329 & -2.489 & $0.035^{*}$ \\
Media context & 73.669 & 19.841 & 3.713 & $0.005^{* *}$ \\
\hline
\end{tabular}

Note. $B=$ unstandardised coefficient; $S E=$ standard error.

$* p \leq .05 . * * p \leq .01$.

Next, we ran a multiple linear regression examining the association between the predictors and the number of words produced by children aged 12 to 16 months. Table 7 shows the parameter estimates of the fitted model.

Table 7

Multiple Linear Regression Coefficients for the Association Between the Predictors and the Number of Words Produced by Children Aged 12 to 16 Months: Full Model

\begin{tabular}{lcccc}
\hline \multicolumn{1}{c}{ Predictor } & $\boldsymbol{B}$ & $\boldsymbol{S E}$ & $\boldsymbol{t}$ & $\boldsymbol{p}$ \\
\hline (Intercept) & -86.207 & 50.321 & -1.713 & 0.162 \\
Media quantity & 2.335 & 5.310 & 0.439 & 0.683 \\
Media content & 2.629 & 8.921 & 0.295 & 0.783 \\
Media context & 9.348 & 7.399 & 1.263 & 0.275 \\
Reading prevalence & -0.413 & 4.318 & -0.096 & 0.928 \\
Family SES & 2.277 & 3.799 & 0.599 & 0.581 \\
Gender & -5.626 & 12.565 & -0.448 & 0.678
\end{tabular}

Note. $B=$ unstandardised coefficient; $S E=$ standard error.

The F-ratio test indicated no significant difference between the full model including the predictors and the null model, $F(6,4)=1.35, p=.401$. As was the case for the regression model with the number of words understood, the stepwise regression retained screen media context only in the regression model. This simple linear model gave the lowest AIC of 57.59. The adjusted $R^{2}$ 
values for the full regression model $\left(R_{\text {Adujsted }}^{2}=0.175\right)$ and the reduced regression model $\left(R_{\text {Adujsted }}^{2}=0.488\right)$ indicated that no additional information was explained by adding other variables to the reduced model, $F(6,10)=0.32, p=.880$.

Table 8 shows the parameter estimates of the reduced model. Screen media context contributed significantly to explaining the variation in the number of words produced by the younger children group. The number of words produced is expected to increase by 10.37 words with a one-unit increase in the composite score of screen media context. This effect is significant at $\alpha=.05$. In summary, the more that caregivers co-engaged with their children in viewing/using screen media and the more they interacted with them while co-viewing, the higher the children's expressive vocabulary scores on the JACDI-WG.

Table 8

Multiple Linear Regression Coefficients for the Association Between the Predictors and the Number of Words Produced by Children Aged 12 to 16 Months: Reduced Model

\begin{tabular}{lcccl}
\hline \multicolumn{1}{c}{ Predictor } & $\boldsymbol{B}$ & $\boldsymbol{S} \boldsymbol{E}$ & $\boldsymbol{t}$ & $\boldsymbol{p}$ \\
\hline (Intercept) & -45.134 & 22.114 & -2.041 & 0.072 \\
Media context & 10.366 & 3.195 & 3.245 & $0.010^{* *}$ \\
\hline
\end{tabular}

Note. $B=$ unstandardised coefficient; $S E=$ standard error.

${ }^{*} p \leq .05 .{ }^{* *} p \leq .01$.

\section{Older Children: 17 to 36 Months}

As described above, we conducted a multiple linear regression examining the association between the predictors and the number of words produced by children aged 17 to 36 months. Table 9 presents the effect of each predictor on the number of words produced, as described by the full multiple regression model. 
Table 9

Multiple Linear Regression Coefficients for the Association Between the Predictors and the Number of Words Produced by Children Aged 17 to 36 Months: Full Model

\begin{tabular}{lcccl}
\hline \multicolumn{1}{c}{ Predictor } & $\boldsymbol{B}$ & $\boldsymbol{S E}$ & $\boldsymbol{t}$ & $\boldsymbol{p}$ \\
\hline (Intercept) & -345.094 & 240.491 & -1.435 & 0.158 \\
Media quantity & 68.817 & 21.106 & 3.261 & $0.002^{* *}$ \\
Media quality & 46.098 & 25.261 & 1.825 & 0.074 \\
Media context & -49.578 & 19.670 & -2.521 & $0.015^{*}$ \\
Reading prevalence & 41.396 & 12.183 & 3.398 & $0.002^{* *}$ \\
Family SES & 21.916 & 13.153 & 1.666 & 0.102 \\
Gender & -24.641 & 53.236 & -0.463 & 0.646 \\
\hline
\end{tabular}

Note. $B=$ unstandardised coefficient; $S E=$ standard error.

$* p \leq .05 . * * \leq .01$.

The F-ratio test was used to compare the contribution of the full regression model in describing the relationship between the response and the independent variables against the null model. A significant difference was found, $F(6,49)=6.43, p<.001$. A stepwise regression was carried out to select variables that decreased the AIC value. The lowest AIC value (594.84) was obtained when child gender was removed from the model. To compare regression models with different numbers of predictors, the adjusted $R^{2}$ was obtained. The adjusted $R^{2}$ values suggest that the reduced model $\left(R^{2}\right.$ Adujsted $\left.=0.382\right)$ describes the variation in the raw number of words produced slightly better than the full model $\left(R^{2}{ }_{\text {Adujsted }}=0.372\right)$. There was no significant difference between the full model and the reduced model, $F(1,59)=0.21, p=.646$.

Table 10 presents the effects of each predictor on the number of words produced, as described by the reduced multiple regression model. The screen media quantity score had the largest positive impact on the number of words produced; the number of words produced is expected to increase by 68.63 words with a one-unit increase in the screen media quantity composite score. In other words, the less that children aged 17 to 36 months were exposed to foreground and background screen media, and the older they were when they started viewing screens, the higher their expressive vocabulary scores. Reading prevalence also showed a 
significant positive association with the number of words produced. A one-unit increase in the reading composite score is expected to increase the number of words produced by 40.70 words. In addition, and unexpectedly, screen media viewing context showed a significant negative association with the number of words produced by children aged 17 to 36 months.

Table 10

Multiple Linear Regression Coefficients for the Association Between the Predictors and the Number of Words Produced by Children Aged 17 to 36 Months: Reduced Model

\begin{tabular}{lcccl}
\hline \multicolumn{1}{c}{ Predictor } & $\boldsymbol{B}$ & $\boldsymbol{S E}$ & $\boldsymbol{\boldsymbol { t }}$ & \multicolumn{1}{c}{$\boldsymbol{p}$} \\
\hline (Intercept) & -344.215 & 238.587 & -1.443 & 0.155 \\
Media quantity & 68.633 & 20.935 & 3.278 & $0.002^{* *}$ \\
Media content & 46.454 & 25.050 & 1.854 & 0.070 \\
Media context & -50.537 & 19.406 & -2.604 & $0.012^{*}$ \\
Reading prevalence & 40.703 & 11.995 & 3.393 & $0.001^{* * *}$ \\
Family SES & 21.240 & 12.969 & 1.638 & 0.108 \\
\hline
\end{tabular}

Note. $B=$ unstandardised coefficient; $S E=$ standard error.

$* p \leq .05 . * * p \leq .01 . * * * \mathrm{p} \leq .001$

Finally, we conducted a multiple linear regression for the association between the predictors and the mean length of the three longest utterances $(\mathrm{M} 3 \mathrm{~L})$ produced by children aged 17 to 36 months. Table 11 presents the effect of each predictor on the M3L produced, as described by the full multiple regression model.

Table 11

Multiple Linear Regression Coefficients for the Association Between the Predictors and M3L Produced by Children Aged 17 to 36 Months: Full Model

\begin{tabular}{lcccc}
\hline \multicolumn{1}{c}{ Predictor } & $\boldsymbol{B}$ & $\boldsymbol{S}$ & $\boldsymbol{t}$ & $\boldsymbol{p}$ \\
\hline (Intercept) & 1.695 & 2.249 & 0.753 & 0.455 \\
Media quantity & 0.416 & 0.197 & 2.109 & $0.040^{*}$ \\
Media content & 0.269 & 0.236 & 1.141 & 0.259 \\
Media context & -0.622 & 0.184 & -3.382 & $0.001^{* *}$ \\
Reading prevalence & 0.356 & 0.114 & 3.126 & $0.003^{* *}$ \\
Family SES & 0.054 & 0.123 & 0.439 & 0.663 \\
Gender & 0.116 & 0.498 & 0.235 & 0.815 \\
\hline
\end{tabular}

Note. $B=$ unstandardised coefficient; $S E=$ standard error.

${ }^{*} p \leq .05 .{ }^{* *} p \leq .01 . * * * \mathrm{p} \leq .001$

The F-ratio test indicated a significant improvement in the prediction of the fitted regression model against the null model, $F(6,49)=4.97, p<.001$. Using stepwise selection, we 
found that dropping screen media content, child gender, and SES gave the best model (the lowest AIC value of 69.09). The adjusted $R^{2}$ values suggest that the reduced model $\left(R^{2}\right.$ Adujsted $\left.=0.32\right)$ was slightly better than the full model $\left(R^{2}{ }_{\text {Adujsted }}=0.30\right)$ in describing the variation of the M3L. There was no significant difference between the full model and the reduced model, $F(3,59)=$ $0.51, p=.676$

Table 12 shows the parameter estimates of the reduced model. The screen media quantity score and the reading prevalence score both had positive effects on the M3L outcomes, while the screen media context score had a negative effect. A one-unit increase in the composite score of screen media quantity and reading prevalence is expected to increase the M3L by 0.4 words and 0.38 words, respectively. A one-unit increase in the screen media context composite score is expected to decrease the M3L by 0.61 .

Table 12

Multiple Linear Regression Coefficients for the Association between the Predictors and M3L Produced by Children Aged 17 to 36 Months: Reduced Model

\begin{tabular}{lcccc}
\hline \multicolumn{1}{c}{ Predictor } & $\boldsymbol{B}$ & $\boldsymbol{S E}$ & $\boldsymbol{t}$ & $\boldsymbol{p}$ \\
\hline (Intercept) & 3.642 & 1.501 & 2.426 & $0.019 *$ \\
Media quantity & 0.402 & 0.194 & 2.073 & $0.043^{*}$ \\
Media context & -0.606 & 0.180 & -3.373 & $0.001^{* * *}$ \\
Reading prevalence & 0.379 & 0.110 & 3.453 & $0.001^{* * *}$ \\
\hline
\end{tabular}

Note. $B=$ unstandardised coefficient; $S E=$ standard error.

$* p \leq .05 . * * p \leq .01 . * * * \mathrm{p} \leq .001$

\section{Discussion}

The aim of the current study was to examine the extent to which each of the three screen media use parameters (quantity, content, and context) predict language outcomes among children under 3 in a group of 85 Saudi Arabic-speaking toddlers. Our analysis revealed two main findings. First, for children aged 12-16 months, screen media context (i.e. the frequency of interactive joint media engagements with the child) correlated positively with expressive and 
receptive vocabulary size. Second, for 17 - to 36 -month-olds, screen media quantity correlated negatively with expressive vocabulary scores and the mean length of the three longest utterances children produced (M3L) whereas reading correlated positively with them.

Our first main finding shows that the more caregivers engaged with their young children in viewing or using screens and the more they verbally interacted with them while co-viewing, the larger expressive and receptive vocabulary size their children had. This finding adds to emerging evidence suggesting a positive association between interactive joint media engagements and early language development (e.g., American Academy of Pediatrics, 2016; Dore et al., 2020; Courage, 2017; Myers et al., 2018; Strouse et al., 2018). In line with Bronfenbrenner's (1979) ecological systems theory, this study shows that caregiver's involvement with their children positively mediates the effects screens can have on children. It is well known that parent-child interactions are exceptionally important for early language development (e.g., Hart \& Risley, 1995; Rodriguez \& Tamis-LeMonda, 2011). Therefore, maintaining positive caregiver-child interactions through verbally interacting during and/or after co-viewing can mitigate adverse effects of screen media use on early language development. Interactive joint media engagements provide children with opportunities for receiving contingent responses and increase conversational turn-taking which are conducive to vocabulary growth (Gilkerson et al., 2018; McGillion et al., 2017). Conversational turns - and not just the sheer quantity of words - have been recently highlighted as key in affecting children's verbal skills (Romeo et al., 2018). Screens, in that sense, can be utilized as prompts for additional, more diverse parent-child interactions.

Unlike its positive relation to language outcomes in younger children, screen media context (i.e., the frequency of interactive joint media engagements with the child) was negatively 
correlated with the expressive vocabulary and M3L of toddlers older than 16 months. While this finding may appear contradictory, it should be remembered that our study did not include an analysis of the interactional features of parental talk while co-viewing. Previous research has indicated that features of parent-child interactions while co-viewing vary depending on several factors, including the types of screen media content and the child's age, and that this variation in parental speech has been linked to differences in outcome measures. For example, Sims and Colunga (2013) found that parents of 30- to 36-month-old children used four types of language when talking to their children during co-viewing: tag questions, label elicitation and feedback, narrating, and wh- questions and explicit labelling. Co-viewing was negatively associated with retention of word learning only when parents used more narrating during the co-viewing (Sims \& Colunga, 2013). Similarly, it is possible that certain interactional features that caregivers in our sample used when co-viewing with their older children might have contributed to the more negative language outcomes. Future research is needed to further explore these possibilities.

Our second main finding shows that among the older children within our sample (17- to 36-month-olds), screen media quantity, (i.e., the amount of time a child spends daily viewing screens, the prevalence of background TV in the child's environment, and the onset age of screen media viewing) correlated negatively with both expressive vocabulary and M3L. This finding highlights the influence of the sheer volume of screen media time over and above the other variables studied. This finding also supports previous research indicating a negative association between the amount of screen time and language outcomes (e.g., Chonchaiya \& Pruksananonda, 2008; Duch et al., 2013; Dynia et al., 2021; Hill et al., 2020; Supanitayanon et al., 2020; Tomopoulos, et al., 2010; van den Heuvel et al., 2019). 
There are concerns that the increasing use of technology is leading to a notable decline in reading and play among children (American Academy of Pediatrics, 2016; Anderson \& Subrahmanyam, 2017; Frost, 2012; Seo \& Lee, 2017). In the current study, we found that screen time was the most prevalent activity among Saudi children under 3 years of age when compared to time spent in reading or playing outdoors which are two activities that have been found to support language development. It has been well established that reading is one of the home literacy environment components that are most significantly and positively linked with concurrent and long-term literacy and language outcomes (e.g., Bus et al., 1995; Farrant \& Zubrick, 2012; Whitehurst \& Lonigan, 1998). In our study, time spent in shared reading activities was predictive of expressive vocabulary and M3L in the older age group, though it was not predictive of vocabulary outcomes in the younger age group, likely because it was a very infrequent activity in younger children. In addition, outdoor play and direct experiences in outdoor settings foster opportunities for child-directed speech, verbal communications, and language development (e.g., Cameron-Faulkner et al., 2017; Cameron-Faulkner et al., 2018; O’Brien \& Murray, 2007). Playing outdoors was low among the children in our sample, which could be attributed to the hot weather in the country and the lack of green space, parks, and outdoor play areas. Although our findings are not able to shed light on whether the increased screen media use directly displaces time spent reading and playing outdoors, our results regarding the discrepancies between time spent on these activities warrant further investigation.

The type of screen media content, as measured by the screen media's target audience, educational value, and content language, was not significantly correlated to language outcomes in either age groups. This finding further supports the notion that infants and toddlers do not seem to benefit from educational content viewed on screens (DeLoache et al., 2010; Krcmar, 
2014; Neuman et al., 2014; Roseberry et al., 2009; Tomopoulos, et al., 2010). It should be noted that there are other variables that could have been included within the content parameter and could have shown different results. For instance, we did not examine the formal features of the content viewed (e.g., rapid pacing, visual special effects, frequent camera cuts, loud music, nonspeech vocalizations), the interactivity and contingency features of the content viewed, or the language- and literacy-promoting strategies employed in the content viewed. To examine these variables, a more detailed qualitative multimodal content analysis would be necessary.

There are a number of key strengths associated with the current study. First, this is one of few studies that have attempted to provide a comprehensive understanding of children's screen media exposure by taking into account not only the amount of time children spend with screens (quantity), but also what children watch (content), and how they watch it (context), as well as the associations between each of these variables and children's language outcomes. Second, this study used an extended version of detailed weekly diaries over a period of 7 weeks to track children's screen media use. Most diary studies have utilized only 1 to 2 days of data and assumed they were representative of other weekdays. Finally, we collected data by using both a diary and a survey. The use of both instruments enabled us to collect rich information about children's daily routines through diaries as well as information about children, parents, and home environments that were not possible to collect with the diaries such as demographic information, the onset age of screen media use, and the number of books at home.

There are, however, also some limitations. First, parent-report measures, in general, are susceptible to socially desirable answers, recall bias, and memory lapses. Secondly, the contradictory results found between the two age groups with regard to the association between the social context of media use and language outcomes call for further research on this topic. 
Future studies may benefit from directly observing what caregivers actually do or say during coviewing. Thirdly, the sample size in the younger age group means that the findings are, to some extent, exploratory and that further research is needed. Finally, we did not ask parents to report in the diaries whether they verbally interacted with their children during co-viewing of mobile media. This data point would have been valuable for the study and should be included in any future research on this topic.

In today's rapidly changing media landscape, understanding children's media use patterns (especially in the early critical developmental years) and examining their association with children's health and development are of extreme importance. This study provides a comprehensive picture of the screen media environment of young children by considering the quantity of the time spent with traditional and new media, a number of content features of the screen media available to children, and the social context of screen media engagements among children. An important take-home message from our study is that, what young children watch or how much they watch it is not as important to their language development as how they watch. Findings from this study and from a large body of prior research continue to show that talking to children matters. 


\section{References}

Alloway, T. P., Williams, S., Jones, B., \& Cochrane, F. (2014). Exploring the impact of television watching on vocabulary skills in toddlers. Early Childhood Education Journal, 42, 343-349. https://doi.org/10.1007/s10643-013-0618-1

American Academy of Pediatrics. (2016). Media and young minds. Pediatrics, 138. https://doi.org/10.1542/peds.2016-2591

Anderson, D. R., \& Pempek, T. A. (2005). Television and very young children. American Behavioral Scientist, 48, 505-522. https://doi.org/10.1177/0002764204271506

Anderson, D. R., \& Subrahmanyam, K. (2017). Digital screen media and cognitive development. Pediatrics, 140(2), S57-S61. https://doi.org/10.1542/peds.2016-1758C

Austin, E. W. (1993). Exploring the effects of active parental mediation of television content, Journal of Broadcasting and Electronic Media, 37, 147-158. https://doi.org/10.1080/08838159309364212

Barr, R., Danziger, C., Hilliard, M. E., Andolina, C., \& Ruskis, J. (2010). Amount, content and context of infant media exposure: A parental questionnaire and diary analysis. International Journal of Early Years Education, 18, 107-122. https://doi.org/10.1080/09669760.2010.494431

Bentley, G. F., Turner, K. M., \& Jago, R. (2016). Mothers' views of their preschool child's screen-viewing behaviour: a qualitative study. BMC Public Health, 16, 718. https://doi.org/10.1186/s12889-016-3440-z

Bornstein, M. H. (2015). Infancy and human development. In J. D. Wright (Ed.), International Encyclopaedia of Social \& Behavioral Sciences (2 ${ }^{\text {nd }}$ ed, Vol. 12, pp. 7-13). Oxford: Elsevier Ltd. https://doi.org/10.1016/B978-0-08-097086-8.23138-3 
Bronfenbrenner, U. (1979). The ecology of human development: Experiments by nature and design. Cambridge: Harvard University Press.

Bus, A. G., van IJzendoorn, M. H., \& Pellegrini, A. D. (1995). Joint book reading makes for success in learning to read: A meta-analysis on intergenerational transmission of literacy. Review of Educational Research, 65(1), 1-21. https://doi.org/10.3102/00346543065001001

Cameron-Faulkner, T., MacDonald, R., Serratrice, L., Melville, J., \& Gattis, M. (2017). Plant yourself where language blooms: Direct experience of nature changes how parents and children talk about nature. Children Youth and Environments, 27(2), 110-124. https://doi.org/10.7721/chilyoutenvi.27.2.0110

Cameron-Faulkner, T., Melville, J., \& Gattis, M. (2018). Responding to nature: Natural environments improve parent-child communication. Journal of Environmental Psychology, 59, 9-15. https://doi.org/10.1016/j.jenvp.2018.08.008

Chonchaiya, W., \& Pruksananonda, C. (2008). Television viewing associates with delayed language development. Acta Paediatrica, 97, 977-982. https://doi.org/10.1111/j.1651$\underline{2227.2008 .00831 . x}$

Common Sense Media. (2017). Behind the Common Sense Media ratings system. https://www.commonsensemedia.org/about-us/our-mission/about-our-ratings

Courage, M. L. (2017). Screen media and the youngest viewers: Implications for attention and learning. In F. C. Blumberg \& P. J. Brooks (Eds.), Cognitive development in digital contexts (pp. 3-28). Elsevier. https://doi.org/10.1016/B978-0-12-809481-5.00001-8 
Dashash, N., \& Safi, S. (2014). JISH Arabic Communicative Development Inventory: Saudi population JACDI: User's guide and technical manual. Jeddah: Jeddah Institute for Speech and Hearing.

DeLoache, J. S., Chiong, C., Sherman, K., Islam, N., Vanderborght, M., Troseth, G. L., Strouse, G. A., \& O’Doherty, K. (2010). Do babies learn from baby media? Psychological Science, 21(11), 1570-1574. https://doi.org/10.1177/0956797610384145

Dore, R. A., Logan, J., Lin, T. J., Purtell, K. M., \& Justice, L. (2020). Characteristics of Children's Media Use and Gains in Language and Literacy Skills. Frontiers in Psychology, 11 (September). https://doi.org/10.3389/fpsyg.2020.02224

Dubai Press Club \& Dubai Media City. (2016). Arab Media Outlook 2016-2018: Youth, content, digital media. http://dubaistudiocity.ae/uploads/AMO-Eng.pdf

Duch, H., Fisher, E. M., Ensari, I., Font, M., Harrington, A., Taromino, C., Yip, J. \& Rodriguez, C. (2013). Association of screen time use and language development in Hispanic toddlers: a cross-sectional and longitudinal study. Clinical Pediatrics, 52, 857-65. https://doi.org/10.1177/0009922813492881

Dynia, J. M., Dore, R. A., Bates, R. A., \& Justice, L. M. (2021). Media exposure and language for toddlers from low-income homes. Infant Behavior and Development, 63(February), 101542. https://doi.org/10.1016/j.infbeh.2021.101542

Farrant, B., \& Zubrick, S. (2011). Early vocabulary development: The importance of joint attention and parent-child book reading. First Language, 32, 343-364. https://doi.org/10.1177/0142723711422626 
Fenson, L., Dale, P. S., Reznick, J. S., Thal, D., Bates, E., Hartung, J. P., Pethick, S., \& Reilly, J. S. (1993). The MacArthur Communicative Development Inventories: User's guide and technical manual. Singular Publishing Group.

Frost, J. L. (2012) The changing culture of play, International Journal of Play, 1(2), 117-130, https://doi.org/10.1080/21594937.2012.698461

Garrison, M. M., Liekweg, K., \& Christakis, D. A. (2011). Media use and child sleep: The impact of content, timing, and environment. Pediatrics, 128, 29-35. https://doi.org/10.1542/peds.2010-3304

Gilkerson, J., Richards, J. A., Warren, S. F., Oller, D. K., Russo, R., \& Vohr, B. (2018). Language experience in the second year of life and language outcomes in late childhood. Pediatrics, 142, e20174276. https://doi.org/10.1542/peds.2017-4276

Hart, B., \& Risley, T. R. (1995). Meaningful differences in the everyday experience of young American children. Baltimore: Paul H. Brookes.

Hill, M. M., Gangi, D., Miller, M., Rafi, S. M., \& Ozonoff, S. (2020). Screen time in 36-montholds at increased likelihood for ASD and ADHD. Infant Behavior and Development, 61(February), 101484. https://doi.org/10.1016/j.infbeh.2020.101484

Hudon, T. M., Fennell, C. T., \& Hoftyzer, M. (2013). Quality not quantity of television viewing is associated with bilingual toddlers' vocabulary scores. Infant Behavior and Development, 36, 245-254. https://doi.org/10.1016/j.infbeh.2013.01.010

Johnson, G. M., \& Puplampu, K. P. (2008). Internet use during childhood and the ecological techno-subsystem. Canadian Journal of Learning and Technology, 34, 168-172. https://doi.org/10.21432/T2CP4T 
Kirkorian, H. L., Pempek, T. A., Murphy, L. A., Schmidt, M. E., \& Anderson, D. R. (2009). The impact of background television on parent-child interaction. Child Development, 80 , 1350-1359. https://doi.org/10.1111/j.1467-8624.2009.01337.x

Krcmar, M. (2014). Can infants and toddlers learn words from repeat exposure to an infant directed DVD? Journal of Broadcasting \& Electronic Media, 58, 196-214. https://doi.org/10.1080/08838151.2014.906429

Lauricella, A. R., Wartella, E., \& Rideout, V. J. (2015). Young children's screen time: The complex role of parent and child factors. Journal of Applied Developmental Psychology, 36, 11-17. https://doi.org/10.1016/j.appdev.2014.12.001

Li, C., Mendoza, M., \& Milanaik, R. (2017). Touchscreen device usage in infants and toddlers and its correlations with cognitive development. Pediatrics \& Health Research, 2, 1-6. https://doi.org/10.21767/2574-2817.100013

Linebarger, D. L., \& Walker, D. (2005). Infants' and toddlers' television viewing and language outcomes. American Behavioral Scientist, 48, 624-645. https://doi.org/10.1177/0002764204271505

Matthews, D., McGillion, M., \& Pine, J. (2016). All about... contingent talk. Nursery World, 25, 17-20. https://doi.org/10.12968/nuwa.2016.25.17

McGillion, M., Pine, J. M., Herbert, J. S., \& Matthews, D. (2017). A randomised controlled trial to test the effect of promoting caregiver contingent talk on language development in infants from diverse socioeconomic status backgrounds. Journal of Child Psychology and Psychiatry, 58, 1122-1131. https://doi.org/10.1111/jcpp.12725 
Madigan, S., Browne, D., Racine, N., Mori, C., \& Tough, S. (2019). Association between screen time and children's performance on a developmental screening test. JAMA Pediatrics, 173(3), 244. https://doi.org/10.1001/jamapediatrics.2018.5056

Myers, L. J., Crawford, E., Murphy, C., Aka-Ezoua, E., \& Felix, C. (2018). Eyes in the room trump eyes on the screen: effects of a responsive co-viewer on toddlers' responses to and learning from video chat. Journal of Children and Media, 12, 275-294. https://doi.org/10.1080/17482798.2018.1425889

Neuman, S. B., Kaefer, T., Pinkham, A., \& Strouse, G. (2014). Can babies learn to read? A randomized trial of baby media. Journal of Educational Psychology, 106, 815-830. https://doi.org/10.1037/a0035937

O’Brien, L., \& Murray, R. (2007). Forest School and its impacts on young children: Case studies in Britain, Urban Forestry \& Urban Greening, 6(4), 249-265. https://doi.org/10.1016/j.ufug.2007.03.006

Radesky, J. S., \& Christakis, D. A. (2016). Increased screen time: implications for early childhood development and behavior. Pediatric Clinics of North America, 63, 827-839. https://doi.org/10.1016/j.pcl.2016.06.006

Rasmussen, E. E., Keene, J. R., Berke, C. K., Densley, R. L., \& Loof, T. (2017). Explaining parental coviewing: The role of social facilitation and arousal. Communication Monographs, 84, 365-384. https://doi.org/10.1080/03637751.2016.1259532

Rideout, V. (2013, October 28). Zero to eight: Children's media use in America 2013. San Francisco, CA: Common Sense Media. https://www.commonsensemedia.org/research/zero-to-eight-childrens-media-use-in$\underline{\text { america-2013 }}$ 
Rodriguez, E. T., \& Tamis-LeMonda, C. S. (2011). Trajectories of the home learning environment across the first 5 years: Associations with children's vocabulary and literacy skills at prekindergarten. Child Development, 82, 1058-1075. https://doi.org/10.1111/j.1467-8624.2011.01614.

Rodriguez, E. T., Tamis-LeMonda, C. S., Spellmann, M. E., Pan, B. A., Raikes, H., Lugo-Gil, J., \& Luze, G. (2009). The formative role of home literacy experiences across the first three years of life in children from low-income families. Journal of Applied Developmental Psychology, 30(6), 677-694. https://doi.org/10.1016/j.appdev.2009.01.003

Romeo, R. R., Leonard, J. A., Robinson, S. T., West, M. R., Mackey, A. P., Rowe, M. L., \& Gabrieli, J. (2018). Beyond the 30-million-word gap: Children's conversational exposure is associated with language-related brain function. Psychological science, 29(5), 700-710. https://doi.org/10.1177/0956797617742725

Roseberry, S., Hirsh-Pasek, K., \& Golinkoff, R. M. (2014). Skype me! Socially contingent interactions help toddlers learn language. Child Development, 85, 956-970. https://doi.org/10.1111/cdev.12166

Roseberry, S., Hirsh-Pasek, K., Parish-Morris, J., \& Golinkoff, R. M. (2009). Live action: Can young children learn verbs from video? Child Development, 80, 1360-1375. https://doi.org/10.1111/j.1467-8624.2009.01338.x

Saudi General Authority for Statistics. (2013). Household expenditure and income survey. https://www.stats.gov.sa/en/37

Saudi General Authority for Statistics. (2016). Demographic survey 2016. https://www.stats.gov.sa/en/4522 
Schmidt, M. E., Rich, M., Rifas-Shiman, S. L., Oken, E., \& Taveras, E. M. (2009). Television viewing in infancy and child cognition at 3 years of age in a US cohort. Pediatrics, 29, 997-1003. https://doi.org/10.1542/peds.2008-3221

Seo, H., \& Lee, C.S. (2017). Emotion matters: What happens between young children and parents in a touchscreen world. International Journal of Communication, 11, 561-580. http://ijoc.org/index.php/ijoc/article/viewFile/4233/1919

Sims, C. E., \& Colunga, E. (2013). Parent-child screen media co-viewing: Influences on toddlers' word learning and retention. Proceedings of the Annual Meeting of the Cognitive Science Society (Vol. 35, pp. 1324-1329). Cognitive Science Society. https://escholarship.org/uc/item/1m4019fp

Smith, M. (2013, November 18). Young Saudis getting creative on YouTube. http://www.reuters.com/article/us-saudi-youtube-idUSBRE9AH0GY20131118

Strouse, G. A., Troseth, G. L., O’Doherty, K. D., \& Saylor, M. M. (2018). Co-viewing supports toddlers' word learning from contingent and noncontingent video. Journal of Experimental Child Psychology, 166, 310-326. https://doi.org/10.1016/j.jecp.2017.09.005

Supanitayanon, S., Trairatvorakul, P., \& Chonchaiya, W. (2020). Screen media exposure in the first 2 years of life and preschool cognitive development: a longitudinal study. Pediatric Research, 88(6), 894-902. https://doi.org/10.1038/s41390-020-0831-8

Takeuchi, L., \& Stevens, R. (2011). The new coviewing: Designing for learning through joint media engagement. New York, NY: The Joan Ganz Cooney Center at Sesame Workshop. https://www.joanganzcooneycenter.org/wpcontent/uploads/2011/12/jgc_coviewing_desktop.pdf 
Taylor, G., Monaghan, P., \& Westermann, G. (2018). Investigating the association between children's screen media exposure and vocabulary size in the UK. Journal of Children and Media, 12, 51-65. https://doi.org/10.1080/17482798.2017.1365737

Tomopoulos, S., Dreyer, B. P., Berkule, S., Fierman, A. H., Brockmeyer, C., \& Mendelsohn, A. L. (2010). Infant Media Exposure and Toddler Development. Archives of Pediatrics \& Adolescent Medicine, 164(12), 1105-1111. https://doi.org/10.1001/archpediatrics.2010.235

Valkenburg, P. M., Krcmar, M., Peeters, A. L., \& Marseille, N. M. (1999). Developing a scale to assess three styles of television mediation: "Instructive mediation," "restrictive mediation," and "social coviewing." Journal of Broadcasting and Electronic Media, 43, 52-66. https://doi.org/10.1080/08838159909364474

van den Heuvel, M., Ma, J., Borkhoff, C. M., Koroshegyi, C., Dai, D. W. H., Parkin, P. C., ... Birken, C. S. (2019). Mobile media device use is associated with expressive language delay in 18-month-old children. Journal of Developmental and Behavioral Pediatrics, 40, 99-104. https://doi.org/10.1097/DBP.0000000000000630

Wartella E., Rideout, V., Lauricella, A. R., \& Connell, S. L. (2014, June). Parenting in the age of digital technology: A national survey (Revised). Center on Media and Human Development, School of Communication, Northwestern University. http://cmhd.northwestern.edu/wpcontent/uploads/2015/06/ParentingAgeDigitalTechnology.REVISED.FINAL_.2014.pdf

Whitehurst, G. J., \& Lonigan, C. J. (1998). Child development and emergent literacy. Child Development, 69(3), 848-872. https://doi.org/10.1111/j.1467-8624.1998.tb06247.x 
World Health Organization. (2019). Guidelines on physical activity, sedentary behaviour and sleep for children under 5 years of age. https://apps.who.int/iris/bitstream/handle/10665/311664/9789241550536eng.pdf? sequence $=1$ \&isAllowed $=y$

Wright, J. C., Huston, A. C., Murphy, K. C., St. Peters, M., Pinon, M., Scantlin, R., \& Kotler, J. (2001). The relations of early television viewing to school readiness and vocabulary of children from low-income families: The early window project. Child Development, 72, 1347-1366. https://doi.org/10.1111/1467-8624.t01-1-00352

Wright, J. C., Huston, A. C., Scantlin, R., \& Kotler, J. (2001). The Early Window Project: "Sesame Street" prepares children for school. In S. M. Fisch \& R.T. Truglio (Eds.), "G" is for "growing": Thirty years of research on children and Sesame Street (pp. 97114). Lawrence Erlbaum.

Zimmerman, F. J., \& Christakis, D. A. (2007). Associations between content types of early media exposure and subsequent attentional problems. Pediatrics, 120, 986-992. https://doi.org/10.1542/peds.2006-3322 